\title{
Effect of Heat Treatment on the In-Plane Anisotropy of As-Rolled 7050 Aluminum Alloy
}

\author{
Huie $\mathrm{Hu}^{1}$ and Xinyun Wang ${ }^{2, *}$ \\ 1 Department of Chemistry and Materials, Naval University of Engineering, Wuhan 430033, China; \\ huhuie@163.com \\ 2 State Key Laboratory of Materials Processing and Die \& Mould Technology, \\ Huazhong University of Science and Technology, Wuhan 430074, China \\ * Correspondence: bigaxun@263.net; Tel./Fax: +86-27-8754-3491
}

Academic Editor: Nong Gao

Received: 22 January 2016; Accepted: 29 March 2016; Published: 2 April 2016

\begin{abstract}
Tensile tests were conducted on both as-quenched and over-aged 7050 aluminum alloy to investigate the effect of heat treatment on the in-plane anisotropy of as-rolled 7050 aluminum alloy. The results showed that the tensile direction has limited effect on mechanical properties of the as-quenched 7050 aluminum alloy. The in-plane anisotropy factors (IPA factor) of tensile strength, yield strength, and elongation in as-rolled 7050 aluminum alloy fluctuate in the vicinity of $5 \%$. The anisotropy of the as-quenched 7050 aluminum alloy is mainly affected by the texture according to single crystal analysis based on the Schmid factor method. Besides, the IPA factor of the elongation in the over-aged 7050 aluminum alloy reaches $11.6 \%$, illustrating that the anisotropy of the over-aged 7050 aluminum alloy is more prominent than that of the as-quenched. The occurrence of the anisotropy in the over-aged 7050 aluminum alloy is mainly attributed to the microstructures. which are characterized by visible precipitate free zones (PFZs) and coarse precipitates in (sub)grain boundaries.
\end{abstract}

Keywords: aluminum alloy; heat treatment; anisotropy; microstructure; texture

\section{Introduction}

Heat treatable high-strength aluminum alloys with high strength-density ratio and excellent mechanical properties have already become the primary structural materials of aircraft and vehicles [1-4]. Plastic forming is often used to achieve the final shape of high-strength aluminum alloy products, during which the anisotropy of workability often takes place. The anisotropy is defined as the difference between property values measured along different axes, and very likely to result in unpredicted material flow behavior. Hence, it is meaningful to reveal the anisotropy of high-strength aluminum alloys during plastic working, so as to precisely control the material flow pattern during forming. Besides, high-strength aluminum alloys in the peak strength state are known to be highly susceptible to stress corrosion cracking (SCC). However, the susceptibility of T6 temper to corrosion can be alleviated through the utilization of over-aged T73 temper, which provides improved corrosion resistance, but with a 10\%-15\% reduction in strength [5]. Therefore, a study of effect of heat treatment, especially over-aging, on the anisotropy of high-strength aluminum alloys during plastic forming is necessary. Moreover, it can also help to deepen the understanding of anisotropic deformation behavior of high-strength aluminum alloys.

It is well known that the anisotropy of aluminum alloys is mainly caused by the crystallographic texture which develops during rolling and heat treatment operation, and the effects of crystallographic texture can be classified into direct effects and indirect one [6-9]. Direct effects are attributed to the orientation of crystals and slip systems with respect to applied stresses and grain morphologies. 
Engler et al. built the correlation of texture and anisotropic properties of the Al-Mg alloy 5005 based on experiment and simulation [10,11]. Crooks et al. concluded that the anisotropy of 2195 aluminum alloy was a direct effect of texture, with no significant contribution from precipitates [12]. Indirect effects are suggested to be caused by work hardening and precipitation during plastic processing, which include the orientation of precipitates with respect to slip systems, the distribution of dislocation densities in differently orientated slip systems and the corresponding distribution of precipitates. Yang et al. reported that the anisotropy of the extruded 7075 aluminum alloy bar was resulted from the elongated grain microstructure and $\{112\}<111>$ and $\{110\}<111>$ crystal textures after extrusion [13]. Bois-Brochu et al. suggested that the strength anisotropy of Al-Li 2099 extrusions might be controlled by the volume fraction of precipitates that could itself be related to the intensity of the $\langle 111\rangle$ fiber texture [14]. Additionally, modeling and simulation work finished by Tome et al. as well as their viscoplastic self-consistent code implied that the microstructure was influential, but the effect became secondary when it was compared to that of the texture [15].

As mentioned in available reports, the anisotropy of aluminum alloys may also be influenced by microstructures, such as the average grain shape [16,17], the topology of second phase particles [18,19], the substructure topology [20-22], etc., which are all closely related with heat treatment processes. As reported in our previous work [23], the microstructure, which considers precipitates and PFZs, while ignores the crystallographic texture, is the primary cause of anisotropy of the 7050 aluminum alloy during high temperature deformation. Thus, it is suggested that the microstructure is also an important cause of aluminum alloys' anisotropy, and heat treatment has a significant influence on the anisotropy of aluminum alloys.

However, few studies have concerned the relationship of heat treatment, texture, microstructure and anisotropy of aluminum alloys, except some works reported by Engler $e t$ al., which considered the correlation of texture, microstructure and anisotropy in 5xxx aluminum alloys during rolling and annealing [10,11,24]. Meanwhile, to the best of our knowledge, reports on the relationship of heat treatment, texture, microstructure and anisotropy of high-strength aluminum alloys are still not available.

Hence, in this paper, tensile tests were carried out to study the effects of heat treatment on the in-plane anisotropy of as-rolled 7050 aluminum alloy sheet, with attention mainly paid to the different heat treatment conditions.

\section{Experimental Section}

Commercial as-hot rolled 7050 aluminum alloy plates with $80 \mathrm{~mm}$ in thickness were used as sample material in this study. The chemical composition of the alloy is Al-(5.7-6.7)Zn-(1.9-2.6)Mg(2.0-2.6) Cu-0.1Zr-0.15Fe-0.12Si-0.10Mn (in wt. \%). Different directions and planes of the as-rolled 7050 aluminum alloy plate are shown in Figure 1. The centerline layer with $2 \mathrm{~mm}$ in thickness was cut out from the as-rolled plate parallel to the rolling plane. Tensile specimens with a $5 \mathrm{~mm}$ gauge width and a $20 \mathrm{~mm}$ gauge length were prepared along the rolling direction (RD), at $45^{\circ}$ from the RD and along the long-transverse direction (LD) respectively, as shown in Figure 2. Before tensile test, the tensile specimens were solid solution treated at $477^{\circ} \mathrm{C}$ for $1 \mathrm{~h}$, and then quenched into water. Half of the as-quenched tensile specimens were then over-aged at $100{ }^{\circ} \mathrm{C}$ for $4 \mathrm{~h}$ followed by another $1 \mathrm{~h}$ at $160{ }^{\circ} \mathrm{C}[25,26]$. Afterward, the tensile specimens were subjected to tensile tests within $24 \mathrm{~h}$ after heat treatment to investigate the effect of heat treatment on the in-plane anisotropy. Tensile tests were carried out on an Instron-5500R universal testing machine (ITW Test \& Measurement, Glenview, IL, USA) at a strain rate of $0.5 \mathrm{~mm} / \mathrm{min}$. For each heat treatment condition, three samples were tested, with the averaged experimental data considered as the final result. The differences of the three measurements are less than 5\%. A Hitachi S-570 scanning electron microscope (SEM, Tokyo, Japan) was used to analyze the fracture surfaces of tested specimens. Electron back scatter diffraction (EBSD, Oxford Instruments plc, Oxford, UK) measurement samples were mounted and electro-polished using 10 vol. $\% \mathrm{HClO}_{4}$ acids in alcohol followed by examined and analyzed using HKL Channel 5 
software in a JEOL 733 electron probe (Advanced Microbeam, Vienna, OH, USA) with an accelerating voltage of $20 \mathrm{kV}$ [27]. The samples for optical microscope (OM) were mounted, polished and etched by Keller solution $\left(1.5 \% \mathrm{HCl}+1 \% \mathrm{HF}+2.5 \% \mathrm{HNO}_{3}+95 \%\right.$ distilled water, in vol. \%) for observation by a ZEISS HAL100 microscope (Carl Zeiss Microscopy, Thornwood, NY, USA). The transmission electron microscope (TEM) samples were thinned to about $50 \mu \mathrm{m}$ followed by electropolish in a double-jet polishing unit operating at $15 \mathrm{~V}$ and $-20{ }^{\circ} \mathrm{C}$ with a $30 \%$ nitric acid and $70 \%$ methanol solution, the disks were observed in a Tecnai 20 microscope (FEI, Hillsboro, OR, USA), operating at $200 \mathrm{kV}$.

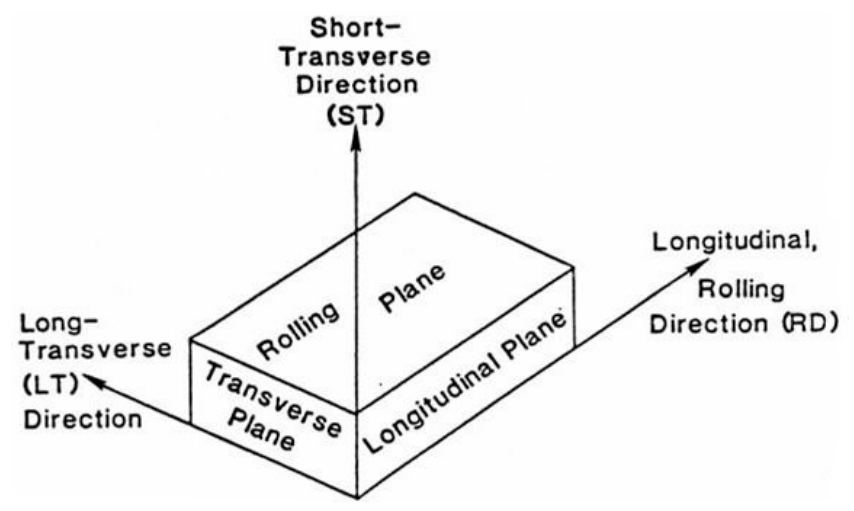

Figure 1. Schematic of different directions and planes in the as-rolled 7050 aluminum alloy plate.

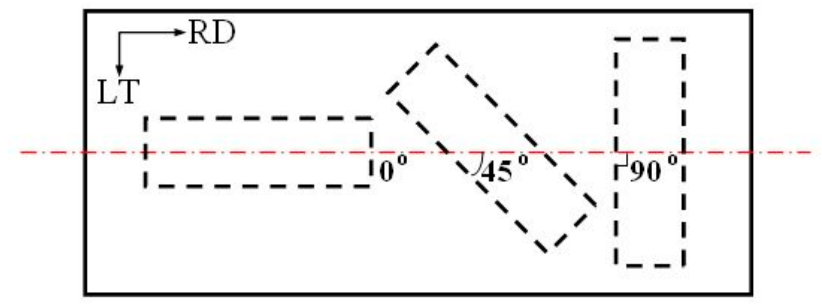

Figure 2. Schematic of tensile specimens with different orientations.

\section{Results}

\subsection{Textures and Grain Microstructures}

It is assumed that all the tensile specimens possess of the same texture components before heat treatment because they all were cut out from the centerline layer of an as-rolled 7050 aluminum alloy with $80 \mathrm{~mm}$ in thickness. Moreover, over-aging at temperatures lower than $200{ }^{\circ} \mathrm{C}$ does not obviously change texture components, thus, both the as-quenched and over-aged tensile specimens also have the same texture components. The variation of orientation densities in $\alpha$ and $\beta$ fibers of the as-quenched 7050 aluminum alloy indicates that a well-developed fiber consisting of the primary Brass orientation $\{011\}<211>\left(35^{\circ}, 45^{\circ}, 90^{\circ}\right)$, the $\mathrm{S}$ orientation $\{123\}<634>\left(57^{\circ}, 37^{\circ}, 63^{\circ}\right)$, and the Copper orientation $\{112\}<111>\left(90^{\circ}, 35^{\circ}, 45^{\circ}\right)$ is evident (see Figure 3). The Brass orientation $\{011\}<211>$ is found to be the strongest orientation along the $\beta$ fiber and the maximal intensity of the Brass orientation $\{011\}<211>$ reaches 35 .

Figure 4 is the optical micrographs showing microstructures in the transverse plane and the longitudinal plane of the as-quenched 7050 aluminum alloy. It is demonstrated that the as-quenched 7050 aluminum alloy consists of elliptical grains in the transverse plane, as shown in Figure 4a. The size of grains in the long-transverse direction is about five times of that in the short-transverse direction. The average intercept length measured by random lines drawn parallel to the short-transverse direction is higher than $50 \mu \mathrm{m}$. The optical micrograph show that microstructures in the longitudinal plane 
consist of highly elongated and band-like grains aligned with the rolling direction (see Figure $4 \mathrm{~b}$ ). Figure 5 presents the optical microstructures of the over-aged 7050 aluminum alloy in the transverse plane, which mainly consist of different sized elliptical grains (see Figure 5a). The microstructures of the over-aged 7050 aluminum alloy in the longitudinal plane contain some large elongated grains distributing in small size grains which most likely are sub-grains (see Figure $5 b$ ). However, the average grain size of the over-aged 7050 aluminum alloy is around $10 \mu \mathrm{m}$ and smaller than that of the as-quenched 7050 aluminum alloy.
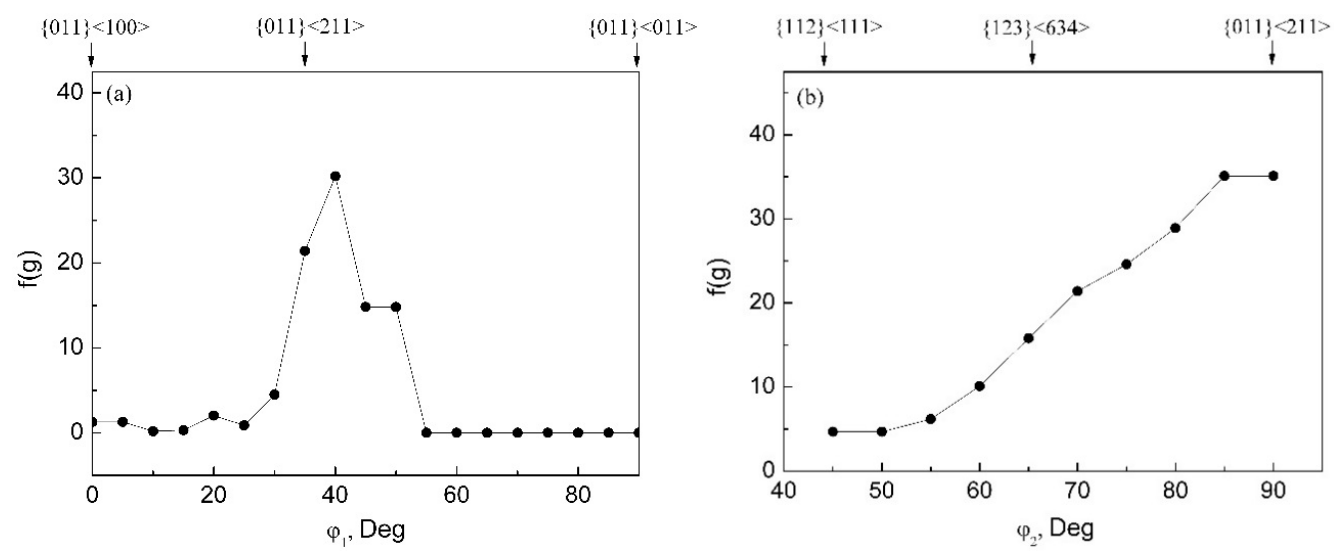

Figure 3. Variation of orientation densities in $\alpha$ and $\beta$ fibers of the 7050 aluminum alloy (a) $\alpha$ fiber; (b) $\beta$ fiber.

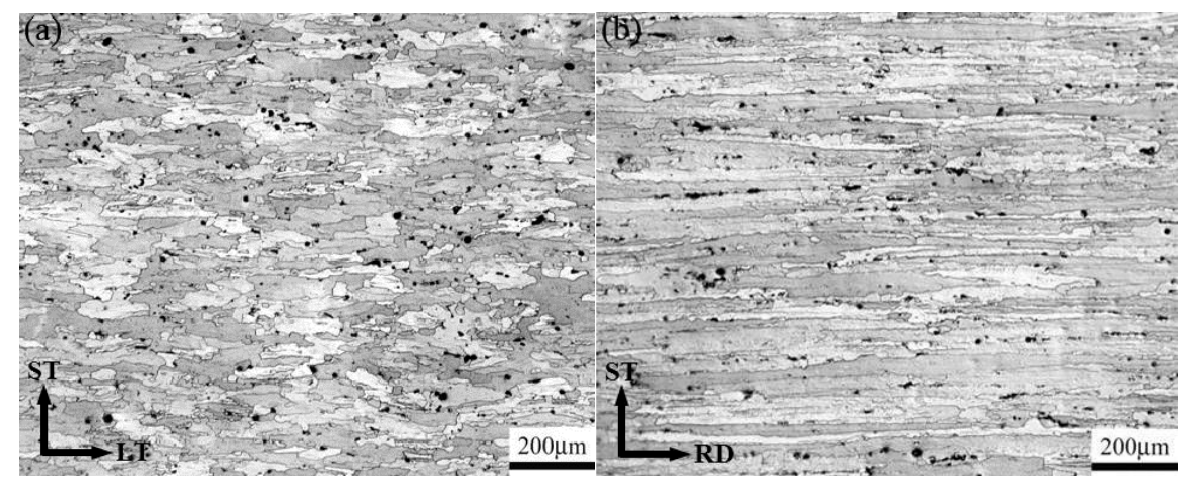

Figure 4. Optical micrographs showing microstructures of the as-quenched 7050 aluminum alloy in (a) the transverse plane; (b) the longitudinal plane.

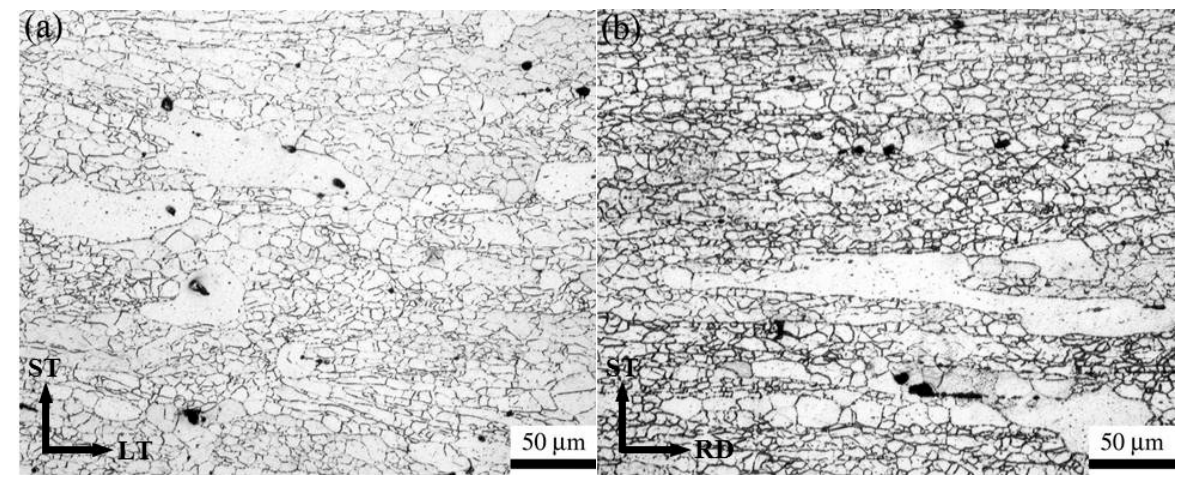

Figure 5. Optical micrographs showing microstructures of the over-aged 7050 aluminum alloy in (a) the transverse plane; (b) the longitudinal plane. 


\subsection{Mechanical Properties}

Figure 6 shows the true stress-strain curves of both as-quenched and over-aged 7050 aluminum alloys stretched along different directions. Mechanical properties obtained according to Figure 6 are listed in Table 1 including tensile strength $\left(R_{\mathrm{m}}\right)$, yield strength $\left(R_{\mathrm{P} 0.2}\right)$ and elongation $(A)$. Table 1 shows that over aging can increase the strength while reduce the elongation of the 7050 aluminum alloy in any direction.
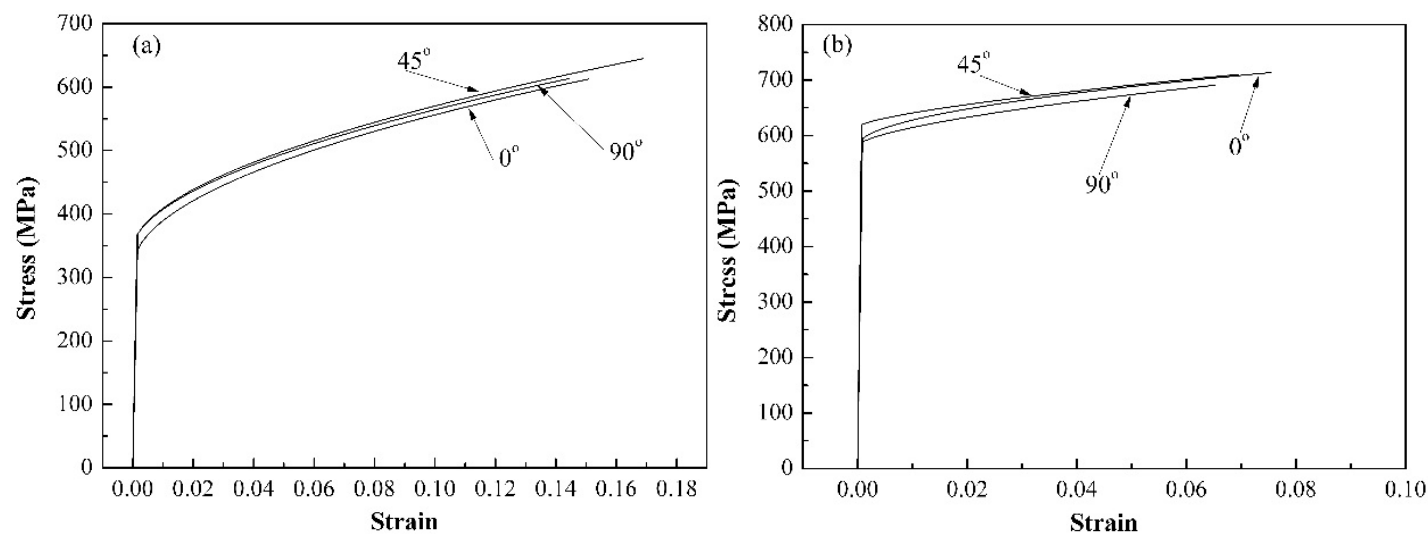

Figure 6. True stress-strain curves of the 7050 aluminum alloy at different tensile directions (a) as-quenched; (b) over-aged.

Table 1. Mechanical properties of the 7050 aluminum alloy under different heat treatment conditions.

\begin{tabular}{ccccccc}
\hline Heat Treatment & \multicolumn{3}{c}{ As-Quenched } & \multicolumn{3}{c}{ Over-Aged } \\
\hline Tensile Directions & $0^{\circ}$ & $45^{\circ}$ & $90^{\circ}$ & $0^{\circ}$ & $45^{\circ}$ & $90^{\circ}$ \\
$R_{\mathrm{m}} / \mathrm{MPa}$ & 610 & 641 & 609 & 717 & 705 & 687 \\
$R_{\mathrm{p} 0.2} / \mathrm{MPa}$ & 315 & 345 & 346 & 581 & 616 & 581 \\
$A / \%$ & 15.44 & 15.6 & 14.08 & 11.68 & 11.08 & 9.56 \\
\hline
\end{tabular}

\subsection{In-Plane Anisotropy}

The in-plane anisotropy of mechanical properties of the 7050 aluminum alloy is characterized by the IPA factor presented in References [28,29], which is defined as:

$$
I P A=\frac{(N-1) X_{\max }-X_{m i d 1}-X_{\operatorname{mid} 2}-\ldots X_{\operatorname{mid}(N-2)}-X_{\min }}{(N-1) X_{\max }} \times 100 \%
$$

where, $N$ is the number of specimens' angle along the rolling direction, $X_{\max }, X_{\min }$ and $X_{\text {mid }}$ are the maximum, the minimum and the rest of mechanical properties respectively. In this study, $N$ is set as 3 , since the tensile specimens were prepared along three directions, including the rolling direction (RD), at $45^{\circ}$ from the RD and along the long-transverse direction (LD), respectively. So IPA factors of mechanical properties of the 7050 aluminum alloy can be calculated by Equation (2).

$$
I P A=\frac{2 X_{\max }-X_{\text {mid }}-X_{\min }}{2 X_{\max }} \times 100 \%
$$

IPA factors of mechanical properties of as-quenched and over-aged 7050 aluminum alloy are calculated according to Table 1 to illustrate the effect of heat treatment on in-plane anisotropy. Figure 7 shows the IPA factors of tensile strength, yield strength, and elongation of as-quenched and over-aged 7050 aluminum alloy samples. It is shown that the IPA factors of tensile strength, yield strength and elongation of the as-quenched 7050 aluminum alloy fluctuate in the vicinity of $5 \%$. However, 
both the IPA factors of tensile strength and yield strength are lower than $6 \%$, and while, the IPA factor of elongation reaches $11.6 \%$ for the over-aged 7050 aluminum alloy, which is higher than that reported in other 7xxx aluminum alloy $[28,29]$. The IPA factor results illustrate that tensile direction has greater effect on elongation than tensile strength and yield strength of the over-aged 7050 aluminum alloy. Besides, the over-aged 7050 aluminum alloy shows stronger anisotropy than the as-quenched 7050 aluminum alloy. So the effect of heat treatment on the in-plane anisotropy of the 7050 aluminum alloy was researched by analyzing the relationship between tensile directions and elongations of the 7050 aluminum alloy with different heat treatment conditions.

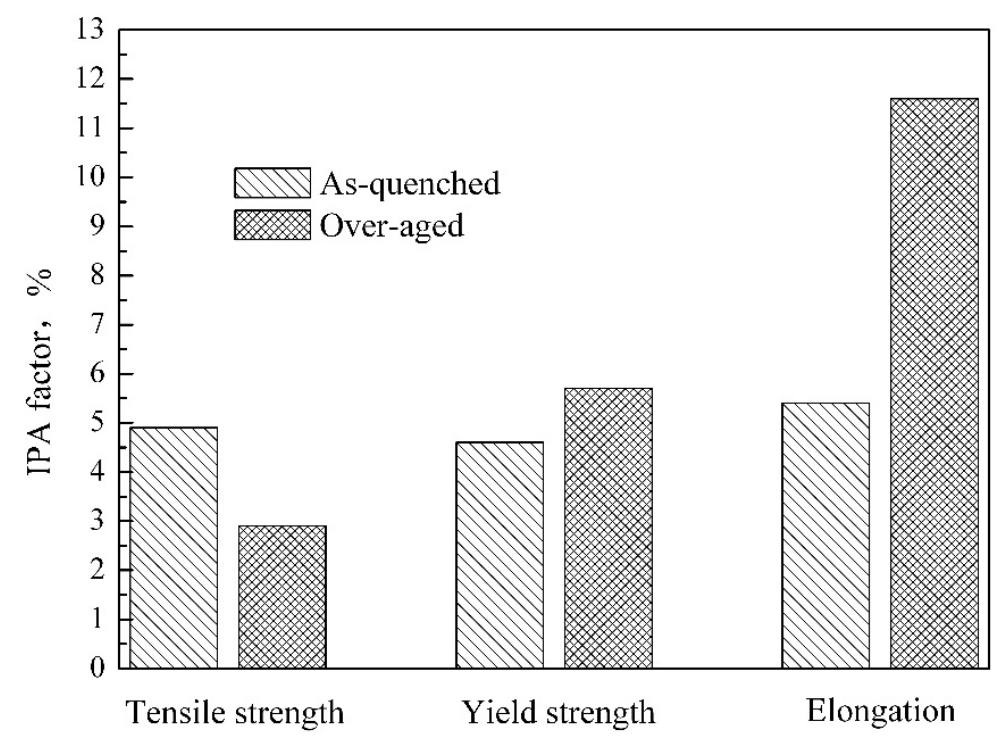

Figure 7. In-plane anisotropy (IPA) factors of mechanical properties of the 7050 aluminum alloy with different heat treatment conditions.

\section{Discussion}

\subsection{In-Plane Anisotropy of the As-Quenched 7050 Aluminum Alloy}

Reference [23] reported that the anisotropy of 7050 aluminum alloy was mainly affected by texture components when the alloy elements of the 7050 aluminum alloy are in solution. It is suggested that the texture components are the primary cause of anisotropy of the as-quenched 7050 aluminum alloy.

Changes of orientation densities in $\alpha$ and $\beta$ fibers of the as-quenched 7050 aluminum alloy imply that the texture components contain the Brass orientation $\{011\}<211>\left(35^{\circ}, 45^{\circ}, 90^{\circ}\right)$, the $S$ orientation $\{123\}<634>\left(57^{\circ}, 37^{\circ}, 63^{\circ}\right)$, and the Copper orientation $\{112\}<111>\left(90^{\circ}, 35^{\circ}, 45^{\circ}\right)$. The intensity of the Brass orientation $\{011\}<211>$ is 35 , much higher than those of the other texture components, indicating that the Brass orientation $\{011\}<211>$ is the main texture component affecting the in-plane anisotropy of the as-quenched 7050 aluminum alloy. The single crystal analysis, which ignores the rotation of the crystal and the interaction between slip systems, will be conducted on the as-quenched 7050 aluminum alloy based on the Schmid factor $(m=\cos (\varphi) \cos (\lambda))$ method as follows.

It is assumed that the as-quenched 7050 aluminum alloy only comprises the Brass orientation $\{011\}<211>$ and is considered as a single crystal. The spatial relationship between four possible $\{111\}$ planes of the as-quenched 7050 aluminum alloy and the Brass orientation $\{011\}<211>$ is shown in

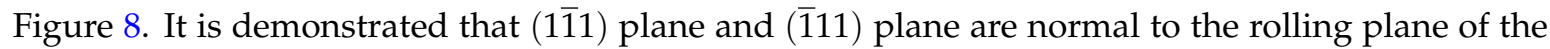
as-quenched 7050 aluminum alloy sheet. The angles between the (111) plane, (11̄ $)$ plane and the rolling plane are all $35.3^{\circ}$. The deformation behavior of the single crystal with the Brass orientation $\{011\}<211>$ along the rolling direction (RD) and the long-transverse direction (LD) was analyzed to represent that of the as-quenched 7050 aluminum alloy. 


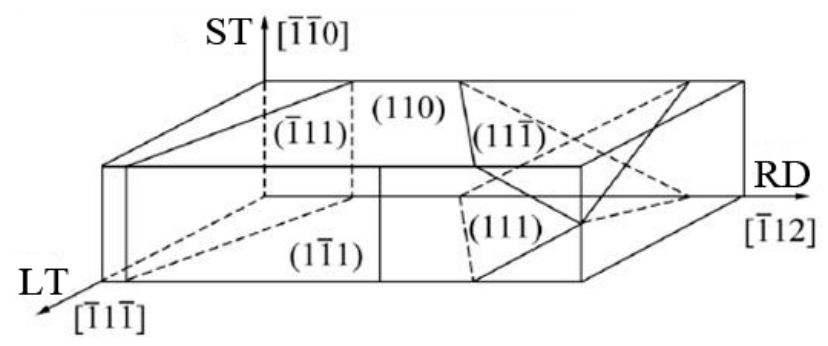

Figure 8. Space relationships of four possible $\{111\}$ slip planes with the Brass orientation $\{110\}<112>$.

Schmid factors of the slip system $\{111\}<110>$ for a single crystal with the Brass orientation $\{011\}<211>$ along the rolling direction (RD), at $45^{\circ}$ from the $\mathrm{RD}$ and along the long-transverse direction (LD) are presented in Table 2. It is shown that the Schmid factors of slip systems (111)[101] and $(11 \overline{1})[011]$ along the rolling direction (RD) are the biggest and reach 0.408 . So the two slip systems with the Schmid factors of 0.408 are the easiest to be activated in the as-quenched 7050 aluminum alloy, which is assumed to be single crystal with the Brass orientation $\{011\}<211>$. For the slip system (111)[101], the angles between it and the short-transverse direction [110], the rolling direction [112], and the long-transverse direction $[\overline{1} 1 \overline{1}]$ are $60^{\circ}, 30^{\circ}$ and $90^{\circ}$, respectively. Meanwhile, for the slip system (111)[011], the angles between it and the short-transverse direction [110], the rolling direction [112], and the long-transverse direction $[\overline{1} 1 \overline{1}]$ are $120^{\circ}, 30^{\circ}$ and $90^{\circ}$, respectively. The two slip systems (111)[101] and (11̄) [011] are the easiest to be activated during tensile deformation along the rolling direction. Hence, during the deformation of the as-quenched 7050 aluminum alloy with the Brass orientation $\{011\}<211>$ single crystal along the rolling direction, the sample thickness decreases, the elongation along the tensile direction (RD) increases, while the sample width almost keeps constant. Besides, $86.6 \%$ stress acts in the tensile direction to make the as-quenched 7050 aluminum alloy elongate in that direction.

Table 2. Schmid factors of the slip system $\{111\}<110>$ for various tensile orientations.

\begin{tabular}{ccccc}
\hline Slip Plane & Slip Direction & $\mathbf{0}^{\circ}$ & $\mathbf{4 5}^{\circ}$ & $\mathbf{9 0}^{\circ}$ \\
\hline \multirow{3}{*}{$(1 \overline{1} 1)$} & {$[110]$} & 0 & 0 & 0 \\
& {$[011]$} & 0 & 0.4330 & 0 \\
& {$[\overline{1} 01]$} & 0 & 0.4330 & 0 \\
\hline \multirow{3}{*}{$(\overline{1} 11)$} & {$[110]$} & 0 & 0 & 0 \\
& {$[0 \overline{1} 1]$} & 0.1361 & 0.3368 & 0.2722 \\
& {$[101]$} & 0.1361 & 0.3368 & 0.2722 \\
\hline \multirow{3}{*}{$(111)$} & {$[1 \overline{1} 0]$} & 0.2722 & 0.0962 & 0.2722 \\
& {$[0 \overline{1} 1]$} & 0.1361 & 0.0364 & 0.2722 \\
& {$[\overline{1} 01]$} & 0.4082 & 0.0598 & 0 \\
\hline \multirow{3}{*}{$(11 \overline{1})$} & {$[1 \overline{1} 0]$} & 0.2722 & 0.0962 & 0.2722 \\
& {$[011]$} & 0.4082 & 0.0598 & 0 \\
& {$[101]$} & 0.1361 & 0.0364 & 0.2722 \\
\hline
\end{tabular}

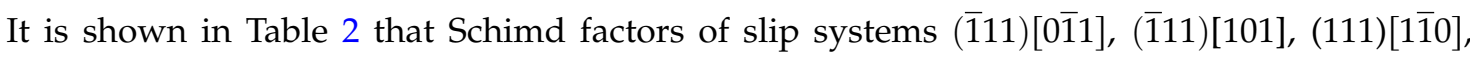
$(111)[0 \overline{1} 1],(11 \overline{1})[1 \overline{1} 0]$ and $(11 \overline{1})[101]$ all are the maximal value of 0.2722 when the tensile direction is $[\overline{1} 1 \overline{1}]$ and along the long-transverse direction (LD). Thus, it is indicated that the six slip systems mentioned above in the as-quenched 7050 aluminum alloy with the Brass orientation $\{011\}<211>$ single crystal were operated at the same time. Table 3 is the shear stress distribution of the six slip systems in the three directions (the rolling direction, the short-transverse direction and the long-transverse direction) in the Brass orientation $\{110\}<112>$ when the tensile direction is along the long-transverse direction. It is shown that during the tensile deformation along the long-transverse direction in the 
as-quenched 7050 aluminum alloy with the Brass orientation $\{011\}<211>$ single crystal, the thickness and width decreases while the elongation of the tensile direction increases. Furthermore, $81.7 \%$ shear stress acts in the tensile direction to make the as-quenched 7050 aluminum alloy elongate in the tensile direction. So the strengths of the as-quenched 7050 aluminum alloy along different directions are similar, as shown in Table 1. The difference of elongation along different directions is small and the IPA factor of elongation is only $5.4 \%$.

Table 3. Shear stress distribution of slip systems in the three directions of the Brass orientation $\{110\}<112>$ when the tensile direction is along the long-transverse direction.

\begin{tabular}{cccc}
\hline Slip System/Direction & $\mathbf{R D}[\overline{1} 12]$ & $\mathbf{S T}[\overline{11} 0]$ & $\mathbf{L T}[1 \overline{11}]$ \\
\hline$(\overline{1} 11)[0 \overline{1} 1]$ & $1 / \sqrt{12}$ & $1 / 2$ & $-2 / \sqrt{6}$ \\
$(\overline{1} 11)[101]$ & $1 / \sqrt{12}$ & $-1 / 2$ & $-2 / \sqrt{6}$ \\
$(111)[1 \overline{1} 0]$ & $-\sqrt{1 / 3}$ & 0 & $2 / \sqrt{6}$ \\
$(111)[0 \overline{1} 1]$ & $1 / \sqrt{12}$ & $1 / 2$ & $-2 / \sqrt{6}$ \\
$(11 \overline{1})[1 \overline{1} 0]$ & $-\sqrt{1 / 3}$ & 0 & $2 / \sqrt{6}$ \\
$(11 \overline{1})[101]$ & $1 / \sqrt{12}$ & $-1 / 2$ & $-2 / \sqrt{6}$ \\
\hline
\end{tabular}

\subsection{In-Plane Anisotropy of the Over-Aged 7050 Aluminum Alloy}

The above analysis shows that the texture components in the over-aged 7050 aluminum alloy, which are similar to those in the as-quenched 7050 aluminum alloy, can only result in slight anisotropy. So the effect of tensile direction on the elongation of the over-aged 7050 aluminum alloy is attributed to the microstructure instead of texture, similarly to what was reported in Reference [30].

TEM images show that precipitates can be founded in the over-aged 7050 aluminum alloy, with small size precipitates uniformly distributing inside grains (see Figure 9a). Coarse precipitates in grain boundaries or subgrain boundaries are visible in the over-aged 7050 aluminum alloy (see Figure 9b). As indicated by arrows in Figure 9b, PFZs are very visible and the widths of the PFZs are less $100 \mathrm{~nm}$. The small size precipitates inside grains have limited influence on the elongation of the as-rolled 7050 aluminum alloy. However, coarse precipitates in grain boundaries or subgrain boundaries and obvious PFZs have a significant effect on the plastic deformation behavior and elongation of the as-rolled 7050 aluminum alloy [23].

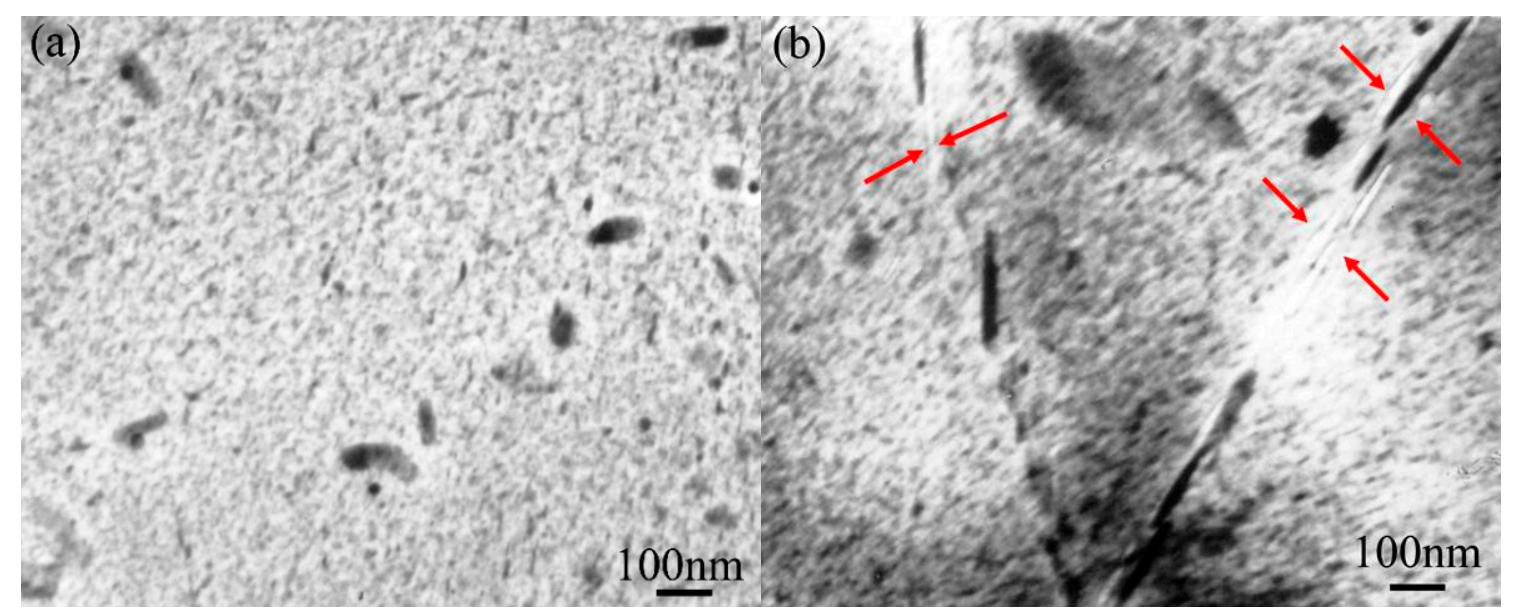

Figure 9. TEM micrographs showing microstructures of the over-aged 7050 aluminum alloy (a) precipitates inside grains; (b) precipitates in grain boundaries and subgrain boundaries.

Figure 10 shows the fracture surfaces of the over-aged 7050 aluminum alloy stretched along different directions. It is implied that the fracture surfaces stretched along different directions are 
different from ordinary ductile transgranular fracture surface of aluminum alloys characterized by dimples with different sizes. The fracture surfaces are intergranular, in which the initial grain structures and grain boundaries can be clearly distinguished. The grain size of the fracture surface of the over-aged 7050 aluminum alloy stretched along the rolling direction is about $10 \mu \mathrm{m}$, which is consistent with the optical microstructure results (see Figures 5a and 10a). Big size elongated grains were observed in the fracture surface of the over-aged 7050 aluminum alloy stretched along the long-transverse direction, which consist of small size grains (see Figure 10b). Figure 9 shows that the size of precipitates in grain boundaries and subgrain boundaries is bigger than that inside grains. It is easy to be eroded for the subgrain boundaries as the grain boundaries. So the small size grains in Figures $5 \mathrm{~b}$ and $10 \mathrm{~b}$ are subgrains in nature. Similar research results have also been reported in our previous studies [23,31,32].

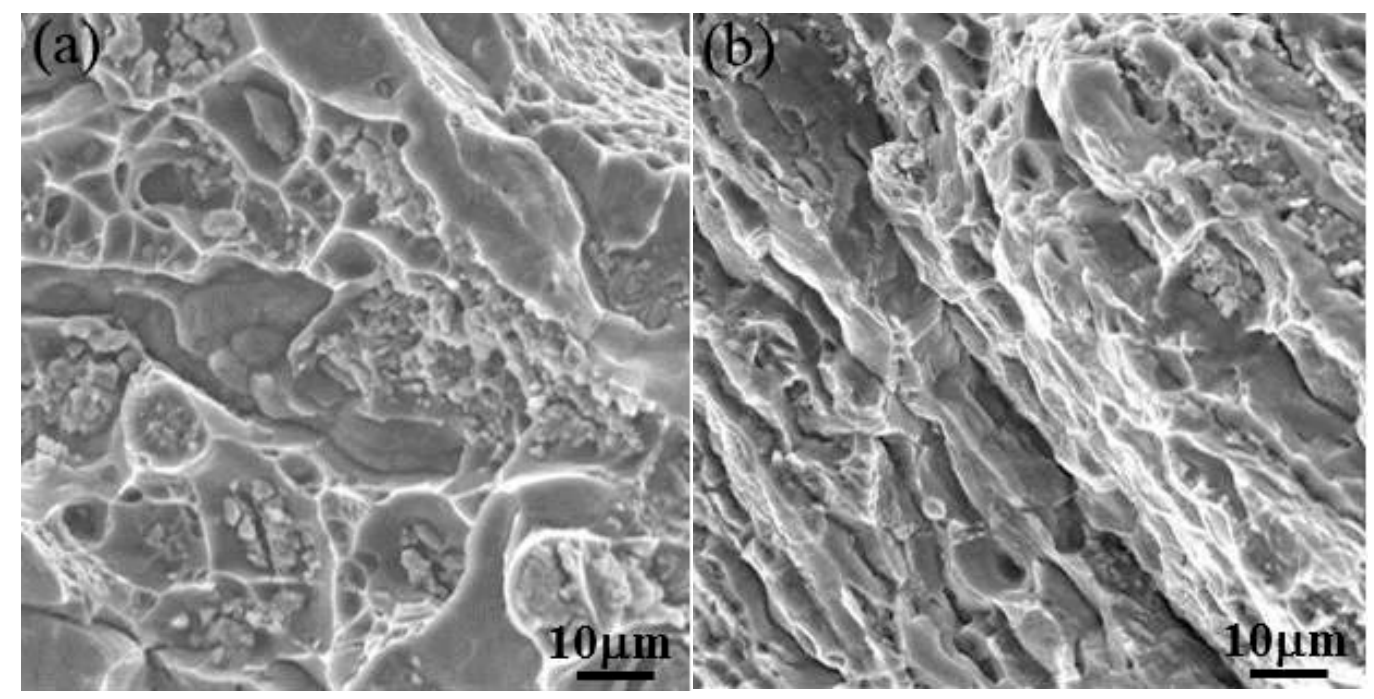

Figure 10. SEM micrographs showing fracture surfaces of the over-aged 7050 aluminum alloy along different directions (a) the rolling direction (RD); (b) the long-transverse direction (LT).

During plastic deformation of the over-aged 7050 aluminum alloy, dislocations bow around, but do not cut through, the precipitates with big size and high hardness. At the same time, the precipitates in subgrain boundaries pin and inhibit the migration of subgrain boundaries. However, the friction of dislocations movement in PFZs is lower than that inside the grains because there are only a few precipitates in PFZs of the over-aged 7050 aluminum alloy. Meanwhile, alternate slipping is easy to occur in PFZs because of few precipitates in (sub)grain boundaries and property of texture (slip systems are nearly parallel to (sub)grain boundaries). Thus, there are more plastic strains in PFZs than those inside the grains. It is to say that the in-plane anisotropy of the over-aged 7050 aluminum alloy has a primary relationship with PFZs' shapes, viz. grains' and subgrains' shapes. The greater difference of grains' and subgrains' shapes in different planes, as shown in Figures 5 and 10 is the primary cause of higher IPA factor in the elongation of the over-aged 7050 aluminum alloy. Figures 5a and 10a show that the grain size in the transverse plane of the over-aged 7050 aluminum alloy is smaller than that in the longitudinal plane. So the PFZs can provide more strains when the over-aged 7050 aluminum alloy is stretched along the rolling direction, than being stretched along the long-transverse direction. Besides, intergranular fractures in Figure 10 indicate cracks in the over-aged 7050 aluminum alloy grow mainly along (sub)grain boundaries. So the smaller the grain size of fracture surfaces, the longer the crack propagation path before failure will be, impling that the elongation of the over-aged 7050 aluminum alloy along the rolling direction is higher than that along the long-transverse direction. The above analyzes also reveal that the elongation and microstructure results are consistent with fracture surfaces. 


\section{Conclusions}

(1) For the as-quenched 7050 aluminum alloy, the tensile direction has little effect on anisotropies of mechanical properties, and the IPA factors of tensile strength, yield strength and elongation fluctuate in the vicinity of $5 \%$.

(2) For the over-aged 7050 aluminum alloy, the difference of IPA factors of mechanical properties is apparent. The tensile direction has a significant effect on the elongation, and the IPA factor of elongation reaches $11.6 \%$.

(3) The intensity of the Brass orientation $\{011\}<211>$ in the as-quenched 7050 aluminum alloy is much higher than those of the other texture components. The influence of texture on the in-plane anisotropy of the as-quenched 7050 aluminum alloy is revealed by building the relationship between the elongation and the Brass orientation $\{011\}<211>$ using the single crystal analysis based on the Schmid factor method.

(4) The microstructures of the over-aged 7050 aluminum alloy are characterized by obvious PFZs and coarse precipitates in (sub)grain boundaries. Deformation is easier to take place in PFZs than that inside grains. The shapes of PFZs, viz. grains' and subgrains' shapes, are the primary cause of the in-plane anisotropy in the over-aged 7050 aluminum alloy.

Acknowledgments: This work was supported by National Nature Science Foundation of China (NSFC-51575522), and State Key Laboratory of Materials Processing and Die \& Mould Technology (P2016-02).

Author Contributions: The preparation of test samples was supported by Hu Huie. The statistical analysis was undertaken by Wang Xin-yun. The paper was written by Hu Huie and Wang Xin-yun.

Conflicts of Interest: The authors declare no conflict of interest.

\section{References}

1. Williams, J.C.; Starke, E.A. Progress in structural materials for aerospace systems. Acta Mater. 2003, 51, 5775-5799. [CrossRef]

2. Deschamps, A.; Brechet, Y. Influence of quench and heating rates on the ageing response of an $\mathrm{Al}-\mathrm{Zn}-\mathrm{Mg}-(\mathrm{Zr})$ alloy. Mater. Sci. Eng. A 1998, 251, 200-207. [CrossRef]

3. Tajally, M.; Emadoddin, E. Mechanical and anisotropic behaviors of 7075 aluminum alloy sheets. Mater. Des. 2011, 32, 1594-1599. [CrossRef]

4. Hu, H.E.; Zhen, L.; Chen, J.Z.; Yang, L.; Zhang, B.Y. Microstructure evolution in hot deformation of 7050 aluminium alloy with coarse elongated grains. Mater. Sci. Technol. 2008, 24, 281-286. [CrossRef]

5. Ranganathal, R.; Anilkumar, V.; Nandi, V.S.; Bhat, R.R.; Muralidhara, B.K. Multi-stage heat treatment of aluminum alloy AA7049. Trans. Nonferrous. Met. Soc. China 2013, 23, 1570-1575.

6. Crumbach, M.; Neumann, L.; Goerdeler, M.; Aretz, H.; Gottstein, G. Through-process modelling of texture and anisotropy in AA5182. Modell. Simul. Mater. Sci. Eng. 2006, 14, 835-856. [CrossRef]

7. Engler, O.; An, Y.G. Correlation of texture and plastic anisotropy in the Al-Mg alloy AA 5005. Solid State Phenom. 2005, 105, 277-284. [CrossRef]

8. Beaudon, A.J.; Dawson, P.R.; Mathur, K.K. A hybrid finite element formulation for polycrystal plasticity with consideration of macrostructural and microstructural linking. Int. J. Plast. 1995, 11, 501-521. [CrossRef]

9. Van Houtte, P. Treatment of elastic and plastic anisotropy of polycrystalline materials with texture. Mater. Sci. Forum 1998, 273-275, 67-75. [CrossRef]

10. Engler, O. Texture and anisotropy in the Al-Mg alloy AA5005-Part I: Texture evolution during rolling and recrystallization. Mater. Sci. Eng. A 2014, 618, 654-662. [CrossRef]

11. Engler, O.; Aegerter, J. Texture and anisotropy in the Al-Mg alloy AA5005-Part II: Correlation of texture and anisotropic properties. Mater. Sci. Eng. A 2014, 618, 663-671. [CrossRef]

12. Crooks, R.; Wang, Z.; Levit, V.I.; Shenoy, R.N. Microtexture, micro structure and plastic anisotropy of AA2195. Mater. Sci. Eng. A 1998, 257, 145-152. [CrossRef]

13. Yang, Y.B.; Xie, Z.P.; Zhang, Z.M.; Li, X.B.; Wang, Q.; Zhang, Y.H. Processing maps for hot deformation of the extruded 7075 aluminum alloy bar: Anisotropy of hot workability. Mater. Sci. Eng. A 2014, 615, 183-190. [CrossRef] 
14. Bois-Brochu, A.; Blais, C.; Goma, F.A.T.; Larouche, D.; Boselli, J.; Brochu, M. Characterization of Al-Li 2099 extrusions and the influence of fiber texture on the anisotropy of static mechanical properties. Mater. Sci. Eng. A 2014, 597, 62-69. [CrossRef]

15. Lebensohn, R.A.; Tomé, C.N.; Maudlin, P.J. A self-consistent formulation for the prediction of the anisotropic behavior of viscoplastic polycrystals with voids. J. Mech. Phys. Solid 2004, 52, 249-278. [CrossRef]

16. Choi, S.H.; Brem, J.C.; Barlat, F.; Oh, K.H. Macroscopic anisotropy in AA5019A sheets. Acta Mater. 2000, 48, 1853-1863. [CrossRef]

17. Delannay, L.; Melchior, M.A.; Signorelli, J.W.; Remacle, J.F.; Kuwabara, T. Influence of grain shape on the planar anisotropy of rolled steel sheets-Evaluation of three models. Compos. Mater. Sci. 2009, 45, 739-743. [CrossRef]

18. Bate, P.; Roberts, W.T.; Wilson, D.V. The plastic anisotropy of two-phase aluminium alloys-I. Anisotropy in unidirectional deformation. Acta Metall. 1981, 29, 1797-1814. [CrossRef]

19. Choi, S.H.; Barlat, F.; Liu, J. Effect of precipitates on plastic anisotropy for polycrystalline aluminum alloys. Metall. Mater. Trans. A 2001, 32, 2239-2247. [CrossRef]

20. Peeters, B.; Seefeldt, M.; Kalidindi, S.R.; van Houtte, P.; Aernoudt, E. The incorporation of dislocation sheets into a model for plastic deformation of b.c.c. polycrystals and its influence on $r$ values. Mater. Sci. Eng. A 2001, 319-321, 188-191. [CrossRef]

21. Mahesh, S.; Tome, C.N.; McCabe, R.J.; Kaschner, G.C.; Beyerlein, I.J.; Misra, A. Application of a substructure-based hardening model to copper under loading path changes. Metall. Mater. Trans. A 2004, 35, 3763-3774. [CrossRef]

22. Li, Z.J.; Winther, G.; Hansen, N. Anisotropy in rolled metals induced by dislocation structure. Acta Mater. 2006, 54, 401-410. [CrossRef]

23. Wang, X.Y.; Hu, H.E.; Xia, J.C. Effect of deformation condition on plastic anisotropy of as-rolled 7050 aluminum alloy plate. Mater. Sci. Eng. A 2009, 515, 1-9.

24. Engler, O. Texture and anisotropy in cold rolled and recovery annealed AA 5182 sheets. Mater. Sci. Technol. 2015, 31, 1058-1065.

25. Rometsch, P.A.; Zhang, Y.; Knight, S. Heat treatment of 7xxx series aluminium alloys-Some recent developments. Trans. Nonferrous. Met. Soc. China 2014, 24, 2003-2017. [CrossRef]

26. Zheng, Y.; Yin, Z.M.; Zhu, Y.Z. Microstructure investigation of a new type super high strength aluminum alloy at different heat-treated conditions. Rare Metal. 2004, 23, 377-384.

27. Cao, W.Q.; Godfrey, A.; Liu, Q. Annealing behavior of aluminium deformed by equal channel angular pressing. Mater. Lett. 2003, 57, 3767-3774. [CrossRef]

28. Singh, R.K.; Singh, A.K.; Prasad, N.E. Texture and mechanical property anisotropy in an Al-Mg-Si-Cu alloy. Mater. Sci. Eng. A 2000, 277, 114-122. [CrossRef]

29. Jata, K.V.; Hopking, A.K.; Rioja, R.T. The ainsotropy and texture of Al-Li alloy. Mater. Sci. Forum 1996, 217-222, 647-652. [CrossRef]

30. Melton, K.N.; Cutler, C.P.; Edington, J.W. Anisotropy during superplastic deformation of the Sn-Pb eutectic alloy. Scr. Metall. 1975, 9, 515-520. [CrossRef]

31. Hu, H.E.; Zhen, L.; Yang, L.; Shao, W.Z.; Zhang, B.Y. Deformation behavior and microstructure evolution of 7050 aluminum alloy during high temperature deformation. Mater. Sci. Eng. A 2008, 488, 64-71. [CrossRef]

32. Zhen, L.; Hu, H.E.; Wang, X.Y.; Zhang, B.Y.; Shao, W.Z. Distribution characterization of boundary misorientation angle of 7050 aluminum alloy after high-temperature compression. J. Mater. Process. Technol. 2009, 209, 754-761. [CrossRef]

(C) 2016 by the authors; licensee MDPI, Basel, Switzerland. This article is an open access article distributed under the terms and conditions of the Creative Commons by Attribution (CC-BY) license (http:/ / creativecommons.org/licenses/by/4.0/). 